\title{
Correction to: The population genetics of parasitic nematodes of wild animals
}

Rebecca Cole* and Mark Viney

\section{Correction to: Parasit Vectors (2018) 11:590 https://doi.org/10.1186/s13071-018-3137-5}

Unfortunately, the original version of this article [1] contains an error. In the section entitled "Influence of anthropogenic disruption on parasitic nematode population genetics", the passage

"Population genetic studies have revealed multiple, distinct lineages of invasive $A$. crassus, suggesting multiple introduction events from different source populations [149, 150]. Furthermore, a southern to northern clinal decrease in its genetic diversity is seen in Europe, suggesting that $A$. crassus was introduced in southern Europe and has since spread northwards [150]."

\section{should read}

"Population genetic studies have revealed multiple, distinct lineages of invasive A. crassus in North America versus Europe, suggesting introductions from different source populations [149, 150]. Fur- thermore, a northern to southern clinal decrease in its genetic diversity is seen in Europe, suggesting that A. crassus was introduced in northern Europe and has since spread southwards [150]."

The authors apologize for the inconvenience caused.

The original article can be found online at https://doi.org/10.1186/s1307 1-018-3137-5.

Published online: 09 October 2019

\section{Reference}

1. Cole R, Viney M. The population genetics of parasitic nematodes of wild animals. Parasit Vectors. 2018;11:590. https://doi.org/10.1186/s1307 $1-018-3137-5$.

\section{Publisher's Note}

Springer Nature remains neutral with regard to jurisdictional claims in published maps and institutional affiliations. 